\title{
De VANGUARDIAS MODERADAS A HETERODOXAS: LA RECEPCIÓN DE LA 'PATAFÍSICA DE Alfred Jarry en la prenSa literaria ESPAÑOLA Y ARGENTINA DEL SIGLO XX
}

\author{
Laura Fólica \\ (Universitat Pompeu Fabra/ Universitat Oberta de Catalunya)
}

"Le Père Ubu, chose fort nécessaire, a réuni l'un et l'autre hémisphère."

Dossiers du Collège de 'Pataphyisique [1958: 46]

¿Por qué distintas vanguardias argentinas rescatan a un autor francés "menor" como es Alfred Jarry? ¿Dónde se sitúa España en esta relación de excéntrica francofilia? ¿Acaso la relación con la literatura francesa permite resignificar una supuesta posición periférica de Argentina o de decadencia de España en el campo intelectual? Para responder a estas preguntas, nos proponemos estudiar la recepción de Alfred Jarry (1873-1907) y la 'Patafísica por él ideada, en la prensa literaria española y argentina en dos momentos históricos distintos: durante las primeras vanguardias que comienzan en la década del veinte y en las segundas vanguardias de los años cincuenta y sesenta. Pero antes de iniciar el viaje hacia tierras hispánicas, resulta oportuno mencionar algunos rasgos del autor y de la obra en su contexto francés con el objetivo de entender mejor por qué y de qué modo serán recuperados a ambos márgenes del Atlántico con el florecimiento de las vanguardias.

Alfred Jarry compuso una extensa obra que ocupa tres tomos de la prestigiosa Bibliothèque de La Pléiade, en la que destaca la saga de Ubú (Ubu roi, Ubu cocu, Ubu enchaîné, Ubu dans la butte, etc.), que el autor fue rescribiendo a lo largo de su vida en otras piezas, textos, cartas o almanaques. Este ejercicio de reescritura continuo llevó a Jarry a identificarse con su personaje en la vida cotidiana desdibujando los límites entre la realidad y la ficción a golpe de revólver, o más 
bien pasándose claramente del lado de la ficción: "N'est-ce pas que c'était beau comme littérature?", preguntó a los asistentes a una velada parisina tras disparar un tiro a la cabeza del escultor Manolo.

Así pues, el Jarry-autor se vuelve un "garante de la ficción" inviritendo la tesis que considera al autor como el referente extraliterario que delegaría su voz a un "ser de papel" omnisciente. Alejado de cualquier intento de verosimilitud realista, Jarry defiende una literatura de tipo antimimética, rupturista tanto con las convenciones ortográficas como con el "buen pensar" burgués. Por eso es que Ubú, además de ser el fantoche tirano que mata al rey de Polonia para quedarse con su trono, se dedica a crear neologismos por medio de la deformación de palabras existentes, como lo ilustra el ya archicitado "merdre", pero también expresiones menos conocidas como "palotins", "cornegidouille", "oneille", "phynance", entre muchas otras. Asimismo, Ubú se arroga el título de doctor en 'Patafísica, esa ciencia o más bien anticiencia "de las soluciones imaginarias" que describe los objetos "por sus rasgos virtuales" y que persigue la "ley de la excepción" y la aceptación de los contarios. ${ }^{1}$

En cuanto a la pieza de teatro Ubu roi (la más llevada a escena de su producción), ${ }^{2}$ esta fue publicada por primera vez en el Mercure de France en 1896, meses antes de su estreno en el Théâtre de I'CEuvre de París, ambas plataformas afínes al simbolismo, que se hallaba, no obstante, en un período de declive. Si bien Jarry cumple con todas las etapas de consagración propias de un escritor simbolista para entrar en el campo literario, como la colaboración en revistas, la publicación de poemas, las traducciones literarias o la participación en salones literarios [Béhar 2009:7-14; Schuh 2014:25-65], una vez en su interior colabora con el ocaso del movimento simbolista al introducir la escatología sobre una escenario más proclive a humores étereos. El día de su estreno la obra generó un escándalo tal que se lo comparó con el suscitado por Hernani de V. Hugo. De ahí en más, una vez calmados los ánimos, se la consideró una pieza precursora de la nueva dramaturgia y de las vanguardias posteriores del siglo en ciernes.

Ahora bien, las características que adquirió la obra en Francia no determinan completamente los sentidos que la pieza puede adoptar en sus recepciones posteriores en otras latitudes y lenguas. De hecho, la circulación de los textos hacia otras áreas lingüísticas no acaba en una reproducción pasiva de sus condiciones productivas sino que responde a una dinámica distinta, puesto que los textos suelen circular sin su contexto de origen en el extranjero. Estos son seleccionados, etiquetados

\footnotetext{
${ }^{1}$ Entre las muchas definiciones, Jarry afirma que "la 'Pataphysique est la science des solutions imaginaires, qui accorde symboliquement aux linéaments les propriétés des objets décrits par leur virtualité" [Jarry 1972:669]; es "la science du particulier, quoiqu'on dise qu'il n'y de science que du général. Elle étudiera les lois qui régissent les exceptions et expliquera I'univers supplémentaire à celui-ci; ou moins ambitieusement décrira un univers que l'on peut voir et que peut-être l'on doit voir à la place du traditionnel" [668].

2 En Francia, Ubu (ya sea la obra Ubu roi como así también adaptaciones con fragmentos de otras piezas) fue llevada a escena setenta y dos veces desde su estreno en 1896 hasta 2016, según la base de datos de Les archives du spectacle, que aunque resulta incompleta sirve para dar una idea general de la frecuencia.
} 
De vanguardias moderadas a heterodoxas: la recepción de la 'patafísica de Alfred Jarry en la prensa literaria española y argentina del siglo xx

y leídos según condicionantes que tienen más que ver con el campo de recepción que con el de partida [Bourdieu 1999:4].

En este artículo nos interesa estudiar la recepción del autor y la obra en el espacio hispánico de la prensa cultural, ${ }^{3}$ acotándolo a España y Argentina, países que, más allá de compartir la lengua castellana, han tenido una historia literaria y un desarrollo editorial muy cercano puesto que los avatares culturales, políticos y económicos de uno han incidido en el otro, a través de viajes voluntarios o exilios obligados de escritores, editores, traductores, así como de una intensa circulación de ideas, textos y corrientes literarias a ambos márgenes del Atlántico, además de una firme tradición traductora.

\section{Las primeras vanguardias "moderadas": la recepción simbolista de Jarry}

¿Cuál fue la relación del autor con las primeras vanguardias hispánicas tanto en España como en Argentina? Es sabido que en la Edad de Plata, España no solo aumenta la producción de literatura local sino también la traducción de las "literaturas universales". La Península se abre a las literaturas extranjeras con traducciones, cuyo punto álgido es alcanzado en 1931, crecimiento que se frena con el comienzo de la Guerra Civil en 1936. En esta etapa conviven representantes de las Ilamadas "generaciones" del 98, 14 y 27, los cuales realizan una lectura de las primeras manifestaciones de las vanguardias europeas desde un patrón simbolista anterior, ya en declive en su propio campo francés. En este sentido, tal y como ilustra el investigador Gallego Roca,

\footnotetext{
no es extraño que Wilde se mezcle con Marinetti en las páginas de Prometeo o que Mallarmé se presente como autor vanguardista en un sentido amplio. El pensamiento de Ortega y la poética de Juan Ramón Jiménez son los que dominan en este tiempo, y ello a pesar de la aparente renovación que suponen los años veinte. [Gallego Roca 2004:482]
}

Si bien hay un intento de ponerse al día con las vanguardias, los investigadores prefieren caracterizar este período español como de un "vanguardismo en precario" o "moderado" [Soria Olmedo 1988; Gallego Roca 2001: 42], no solo porque la forma y el lenguaje para recibir las vanguardias se acercan más al simbolismo que a nuevos enfoques lingüísticos o formales (por ejemplo, Revista de Occidente publicó El cementerio marino de Paul Valéry), sino también porque

\footnotetext{
${ }^{3}$ Si bien aquí nos centramos solo en la recepción en la prensa de la literatura de Jarry, conviene recordar que nuestro autor, al igual que muchos escritores vanguardistas, importó técnicas de las artes pictóricas (por ejemplo, se interesa en la capacidad sintética y simultánea que ofrece la pintura, ejemplicada sobre todo en las telas de Paul Gaugin) y de las artes menores como las marionetas, dada su capacidad de representar al personaje a través del gesto hierático de la madera carente de psicologismo. En nuestra tesis doctoral [Fólica 2017] estudiamos esta relación interartísitca en la obra de Jarry así como también en su posterior recepción en las artes plásticas españolas, gracias a artistas como Picasso o Miró.
} 
el vanguardismo de la Edad de Plata es de menor virulencia que su homólogo francés: la búsqueda no es asestar un golpe contra una institución consolidada, sino completar el canon literario faltante.

En cuanto a la prensa literaria del período, y si bien se podría vincular a Jarry con los simbolistas tardíos o "menores", como señala Anoll [1995:177-178], su nombre está ausente en revistas asociadas a la Edad de Plata. ${ }^{4}$ No obstante, en la prensa de la época hemos hallado referencias que remiten a originales franceses de "literatura rara". Así, la primera mención es de 1911, en una lista de venta de libros de ocasión de una biblioteca particular "compuesta de obras rarísimas y escogidas de autores clásicos y modernos". Allí se ofrece un ejemplar de "Almanach du Père Ubu. Un petit volume. (Por Alfred Jarry et Bonnard. Curiosidad muy rara)". (España, Madrid, 9/4/1915, p. 11).

Las siguientes menciones de Jarry se vinculan con la muerte de Apollinaire (La lectura, Madrid, 9/1918, p. 369) y con el artículo del propio Apollinaire "El espíritu nuevo y los poetas", publicado como tributo al poeta en ocasión de su fallecimiento, en Cosmópolis ( $n^{\circ}$ 1, 1/1919, p. 22). Esta revista se interesó por la literatura francesa tratando de copiar tardíamente (entre 1919 y 1940) y bajo la dirección de E. Gómez Carrillo la revista simbolista Mercure de France (1890). Allí mismo, en mayo de 1920 ( $n^{\circ} 17$, p. 127), Jarry es mencionado en la reseña del libro póstumo de Laurent Tailhade: Quelques fantômes de jadis. En 1922 (nº 39, 3/1922, p. 68-70), con las iniciales H. C. (del crítico Hernández Cata), se publica el primer comentario en España sobre Ubu roi, con el título de "El escándalo del rey bastardo". La reseña vuelve a aparecer sin cambios en La Esfera en marzo de 1922 (no 428, p. 6).

Tras un análisis detallado de la edición, Hernández Cata define la obra como "una sátira burda, escrita con desenfado cercano al descoco", y la relaciona con el ultraísmo español a causa del juego con el lenguaje:

[...] es una obra bufa y a veces es patológica; proyéctase en algunas de sus escenas la sombra de Macbeth grotesco, y ofrece, quizás como su más saliente originalidad, la frecuente repetición de la palabra cambroniana ${ }^{5}$ con una sintaxis nueva: la interpolación de una erre, lo cual le da cierto aspecto ultraísta. [Hernández Cata 1922:6]

\footnotetext{
${ }^{4}$ Para ello, nos referimos al portal de "Revistas de la Edad de Plata", compuesto por 30 títulos: 1616, Ambos, Arte, Caballo verde para la poesía, Carmen, Cruz y Raya, Ddooss, Favorables París Poema, Gallo, Héroe, Hojas de poesía, Horizonte, Índice, La gaceta literaria, Lola, Los cuatro vientos, Mediodía, Meseta, Música, Noreste, Octubre, Papel de Aleluyas, Poesía, Prisma, Residencia, Ronsel, Sí, Ultra, Un enemic del poble, Verso y prosa.

${ }^{5}$ Este fue el eufemismo más usado en la crítica de la época para referirse a la palabra "merdre" sin tener que nombrarla. Deriva del apellido "Cambronne", militar que tras caer herido en la batalla de Waterloo habría gritado "mierda".
} 
De vanguardias moderadas a heterodoxas: la recepción de la 'patafísica de Alfred Jarry en la prensa literaria española y argentina del siglo xx

En la crítica citada, se caracteriza la obra como "grotesca", "sátira bufa" y "esperpéntica", relacionándola claramente con el género creado con Valle-Inclán (1866-1936), asociación que continuará presente en la recepción posterior de Jarry en España.

En 1922, en un artículo sobre la reforma del panorama teatral español ("La reforma del teatro", La Voz, Madrid, 23/10/1922, p. 1), se alude a Ubu roi en relación con la obra del dramaturgo español Enrique García Álvarez (1873-1931). Allí se crítica el teatro de ambos por ser excesivamente grosero: "García Álvarez y Jarry coinciden en explotar hasta sus últimas consecuencias la comicidad del vocablo o de las acciones físicas que supone el vocablo de Cambronne. Acaba de crearse el género intestinal".

García Álvarez, amante de retruécanos y juegos de palabras en sus obras teatrales, fue un dramaturgo que llegó a ser calificado, como el autor "más desorbitado, el menos burgués, quizá el maestro de los que después empezamos a cultivar lo disparatado" por otro autor singular como $\mathrm{F}$. Mihura [1992:13]. En la crítica de La Voz, sin embargo, el articulista juzga que habría que renovar la escena, pero evitando caer en la grosería practicada por ambos dramaturgos: "El teatro es la mejor escuela de costumbres, y no es posible tolerar su abyección", sentencia.

Recapitulando, en las primeras referencias al mundo de Jarry en la prensa española de comienzos de siglo marcada por el simbolismo se plantea una relación con cierta dramaturgia local vinculada, sobre todo, con el esperpento de Valle-Inclán y con un grotesco que a veces cae en la grosería, censurable para el gusto de época. ¿Pero qué ocurría por esos años en el hemisferio sur?

En Argentina, la década de los años veinte asistió al desarrollo de proyectos revisteriles de espíritu vanguardista, cargados de intenciones, diálogos y debates con los movimientos de vanguardia europeos y que dieron cuenta de una búsqueda de modernización del campo cultural más que de un afán de ruptura con el mismo. En algunas de sus páginas se hará referencia a Jarry, dando cuenta de una recepción simbolista tardía al igual que ocurría en España.

Sin negar la importancia de las primeras publicaciones más asociadas al ultraísmo como Los raros (1920), Prisma (1921-1922) y Proa (1922-1926), lo cierto es que el espíritu de vanguardia artística argentina se afianza en la revista Martín Fierro (en su segunda época, de 1924 a 1927 y bajo la dirección de Evar Méndez). En sus páginas publica "un grupo de jóvenes talentosos influidos por el ultraísmo español, el futurismo de Marinetti y el creacionismo de Huidobro" [García Haymes 2011:77], entre los que destacan Jorge Luis Borges, Oliverio Girondo, Eduardo González Lanuza, Ricardo Güiraldes, entre otros. 
La revista planteaba la emergencia de una "nueva sensibilidad", como enunciaba en su manifiesto (Martín Fierro, no 4, 15/05/1924, p.1-2), redactado por el poeta Oliverio Girondo:

\footnotetext{
Martín Fierro siente la necesidad imprescindible de definirse y de llamar a cuantos sean capaces de percibir que nos hallamos en presencia de una NUEVA sensibilidad y de una NUEVA comprensión, que, al ponernos de acuerdo con nosotros mismos, nos descubre panoramas insospechados y nuevos medios y formas de expresión. [AA. VV. 1995:25-26]
}

A partir de esta nueva sensibilidad, los autores martinfierristas buscaban consagrarse en un nuevo espacio literario, no tanto para obtener un rédito económico, sino más bien para alcanzar el reconocimiento simbólico como escritores "criollos". En ese sentido, el nacionalismo cultural argentino de esta vanguardia se centró en recuperar un criollismo basado en una lengua oral manejada con soltura y que se alejaba tanto de las lenguas prehispánicas como del español peninsular [Sarlo 1997a:211-268]. La "fe en nuestra fonética", proclamada en su manifiesto, llevó a los martinfierristas a querer cortar de un "tijeretazo a todo cordón umbilical" con España.

De ahí que tomaran partido de forma inmediata en la polémica lanzada por De Torre en el número 8 de La Gaceta Literaria (15 de abril de 1927) sobre Madrid como "meridiano intelectual de Hispanoamérica". Frente a la crítica de la "captación" e "inmantación" que ejercía París en los jóvenes escritores "hispanoparlantes", De Torre proponía situar a Madrid como el "más certero punto meridiano, como la más auténtica línea de intersección entre América y España", ya que América sería la "prolongación" del área intelectual española; no ejercería dominación alguna, sino pura relación fraterna entre hablantes de la misma lengua. En su argumentación, De Torre sitúa en un mismo nivel la influencia española y la francesa sobre América, premisa que rechazarán los martinfierristas.

Estos respondieron de inmediato en el número 42 (10 de julio de 1927) en "Un Ilamado a la realidad" [AA.VV. 1995:356-357] atacando especialmente la supuesta unidad lingüística española entre naciones hermanas: "Pero nosotros ya hemos progresado mucho, tanto que no podemos decir en qué idioma hablamos. Nuestra ilusión debe ser la de echar a perder de tal manera el castellano que venga un español y no entienda nada de lo que le digamos" [356], augura Pablo Rojas Paz.

Con el objetivo de descentrar el español en América, los escritores criollos practicaban el poliglotismo, tal y como afirma Raúl Sacalabrini Ortiz: 
De vanguardias moderadas a heterodoxas: la recepción de la 'patafísica de Alfred Jarry en la prensa literaria española y argentina del siglo xx

\footnotetext{
Se les escapa advertir [a los de La Gaceta Literaria] que en el fondo hay una cuestión de cultura; que hoy nos es tan fácil aprender el francés o el italiano como el castellano; que ya no se puede hablar de identidad lingüística porque todos somos algo políglotas y estamos acostumbrados a escribir en idioma propio. [357]
}

Se trata, en realidad, de un "buen" poliglotismo, aquel hablado por los criollos, ${ }^{6}$ el que les permitía apropiarse del capital literario francés sin pasar por la mediación de España. Por ejemplo, si bien rescataban a Gómez de la Serna como escritor vanguardista, recuperaban a la par otras lecturas europeas. Dicha estrategia es rastreada por Beatriz Sarlo en Borges "quien, en el espacio de Martín Fierro, propone las lecturas europeas más sofisticadas y libres de la previsibilidad que unió, en el periódico, a Apollinaire, Valery Larbaud, Supervielle y Giraudoux" [Sarlo 1997a:240].

Así pues, los martinfierriestas apuntaban a valorar la tradición criolla al tiempo que buscaban ponerse al día respecto de lo que sucedía en Europa, yendo más allá de España. Aunque la recuperación local para entrar en sintonía internacional pueda parecer paradójica, queda claro que esta debe leerse como una toma de posición respecto de España y su intento fallido de dominación intelectual.

Asimismo, dicha toma de posición sobre la unidad o diversidad del español tuvo una cara menos simbólica y más material en el mercado editorial. La política cultural española que apuntaba a mejorar la situación del libro español entre 1892 y 1938 estuvo centrada en las traducciones vendidas a Hispanoamérica: España quería ser el introductor de autores españoles pero también el mediador de América Latina con respecto a Europa. Su interés comercial para mejorar las exportaciones del libro español Ilevaron al país a adoptar estratégicamente el "americanismo" como discurso cultural. En la década del cuarenta, Argentina buscará, a su turno, posicionarse como país traductor para América Latina y la Península, ocupando el rol que había tenido hasta entonces España [Espósito 2010:515-537].

En el marco de la polémica por el meridiano, si bien De Torre se quejaba por la poca presencia del libro español en América, los martinfierristas denunciaban, a su turno, la ausencia del libro americano en España. Para ello retoman una polémica entre el autor argentino Eduardo Schiaffino y el español Eduardo Gómez de Baquero en El Sol de Madrid sobre el desigual acceso al libro americano frente al español [AA. VV. 1995: 46-47]. Schiaffino advertía que el libro americano

\footnotetext{
${ }^{6}$ Esta es la tesis de Sarlo [1997b:269-288], quien sugiere que los escritores de vanguardia distinguían entre una "buena heterogeneidad" del criollo europeo, que domina su lengua materna y que habla también francés e inglés, y una "mala heterogeneidad" del inmigrante italiano, que no domina con naturalidad el rioplantese.
} 
solía ser publicado en Madrid o Barcelona por conveniencia económica pero que se enviaba a América sin distribuirse siquiera en librerías españolas.

En ese peculiar contexto, la recuperación de Jarry por Martín Fierro, quien hace su entrada en el no 14-15 (24/01/1925), puede ser entendida como una lectura de carácter europea que permite apuntalar un sistema de referentes literarios por fuera del español. En un artículo titulado "Cuatro aspectos de la poesía moderna", el director de la revista, Evar Méndez, presenta al autor a través de la traducción del poema "Le bain du roi", que refiere a los pasos de Ubú en tierras patagónicas. Lo acompañan otros poemas de escritores asociados al simbolismo como Maurice Du Plessys, Laurent Thailhade y Albert Samain. A continuación, citamos el original francés y su traducción, reproducida en su edición facsimilar [AA. VV. 1995:100].

\section{Le Bain du roi}

Rampant d'argent sur champ de sinople, dragon

Fluide, au soleil la Vistule se boursoufle.

Or le roi de Pologne, ancien roi d'Aragon,

Se hâte vers son bain, très nu, puissant maroufle.

Les pairs étaient douzaine: il est sans parangon.

Son lard tremble à sa marche et la terre à son souffle;

Pour chacun de ses pas son orteil patagon

Lui taille au creux du sable une neuve pantoufle.

Et couvert de son ventre ainsi que d'un écu

Il va. La redondance illustre de son cul

Affirme insuffisant le caleçon vulgaire

Où sont portraicturés en or, au naturel,

Par derrière, un Peau-Rouge au sentier de la guerre

Sur son cheval, et par devant, la Tour Eiffel.

La traducción publicada en Martín Fierro es la siguiente:

\section{El Baño del Rey}

Rampante de plata sobre campo de sinople, dragón

Fluido al sol el Vístula se hincha. 
Los pares eran docena: él es sin parangón,

Su p.ch. tiembla a su marcha y la tierra a su soplo;

Para cada uno de sus pasos su pie patagón

Le talla en el hueco de la arena una nueva pantufla.

Y cubierto por su vientre como con un escudo

Va. La redondez, ilustre de su c.I.

Afirma insuficiente el calzoncillo vulgar

Donde están retratados en oro, al natural,

Por detrás, un Pie-Roja camino de la guerra

A caballo, y por delante, la Torre Eiffel.

Alfred Jarry (Trad. de Evar Mendez)

Si bien hemos dicho que Martín Fierro se erige como una revista de vanguardia criolla, advertimos que el carácter vanguardista no afecta a la traducción del poema, ya que en ella prevalece un rasgo de moderación y hasta de decoro más que de rebeldía. El director de la publicación, que oficia aquí de traductor, censura las palabras de referencia sexual como "lard" y "cul", que traduce por "p.ch." y "c.l." elidiendo las vocales de "picha" y "culo". De este modo, deja el espacio en blanco para que el lector lo complete a su turno y bajo su entera responsabilidad. Queda claro que del "moderatismo" [Sarlo 1997a:223] que prevalece en la revista no están exentas las traducciones.

Luego de las tres primeras décadas en las que el vanguardismo moderado, tanto español como argentino, rescata publicaciones simbolistas -y en las que Jarry aparece marginalmente-con el objetivo de ponerse al día respecto de las letras europeas, resulta interesante comentar la reaparición del personaje de Ubú de la mano del poeta Luis Cernuda durante la Guerra Civil española.

El poeta ensaya una primera traducción de la obra teatral, por encargo de María Teresa de León para poner en escena en el Teatro de Arte y Propaganda en 1937. El objetivo es claro: recuperar el guiñol como un medio de propaganda antifascista. Si bien la traducción está perdida, ${ }^{7}$ esta podría

\footnotetext{
7 Esto es indicado por Emilio Barón en su artículo "Luis Cernuda, traductor (sus versiones de poemas franceses, alemanes e ingleses)" [1998:37]. Dicha información nos ha sido confirmada por el heredero de Cernuda, Ángel Yanguas Álvarez de Toledo Cernuda, nieto del poeta y gran conocedor de sus manuscritos, así como también por los responsables de los centros de documentación de la Residencia de Estudiantes de Madrid y el Centro Cultural de la Generación del 27 de Málaga, instituciones que se reparten los fondos del escritor.
} 
relacionarse, por temática y proximidad temporal, con dos textos críticos que Cernuda escribe para El mono azul, revista de la Alianza de Intelectuales Antifascistas para la Defensa de la Cultura.

El 14 de octubre de 1937, el poeta publica el artículo "Sobre la situación de nuestro teatro" [Cernuda 2007a:130-133], donde lamenta la falta de medios que alienten la aparición de una nueva dramaturgia. Critica el panorama literario y dramático del pasado reciente: "Se ha dicho que no tenemos novelistas ni dramaturgos. ¿Y cómo los vamos a tener, desdichados de nosotros, si no nos dejaban tenerlos?" [131]. Para Cernuda, el panorama teatral era vergonzoso antes de iniciarse la guerra: "No creo que quepa mayor abyección que aquella en que había caído nuestro teatro representado. Hasta tal punto que el rubor coloreaba las mejillas al leer cualquier cartelera de espectáculos" [132]. En ese sentido, la guerra habría marcado la desaparición de "esas obras teatrales embrutecedoras" [132]. Pero Cernuda advierte que seguían sin darse ninguna rectificación: "¿No siguen embruteciéndonos, como si aquí no ocurriera nada, ante los engendros que le sirven sobre las tablas? Piénsese que no todo sigue igual en este punto, sino que aún está mucho peor" [132]. Por eso, el poeta llama a trabajar con el objetivo de mejorar la escena, central para el surgimiento de nuevos dramaturgos.

Este pedido de mejorar la dramaturgia en cartel con el objetivo de alentar la producción local se hace aún más manifiesto en su segundo artículo, "Un posible repertorio teatral", del 28 de octubre de 1937, en El mono azul [Cernuda 2007b:134-136]. Habiendo ya formulado su crítica al panorama teatral local, en este segundo texto, Cernuda se vuelve más preciso y plantea la necesidad de la traducción teatral para fomentar un teatro local, ilustrando así la función primaria que desempeñaría la traducción en sistemas literarios en crisis para la rápida generación de literatura propia [Even-Zohar 1990:45-51]. En ese sentido, el poeta abre el artículo sentenciando: "Cualquier repertorio teatral que con gusto y juicio quiera formarse en España, debe forzosamente acudir a lo extranjero" [134].

De España, declara que "solo Valle-Inclán puede contar" para el fin de siglo y "de los escritores más recientes, únicamente dos nombres pueden escogerse: los de Federico García Lorca y Rafael Alberti. Ahí termina hoy por hoy, el número de dramaturgos contemporáneos españoles que deben figurar en programas de verdadero teatro" [134]. En especial, señala la necesidad de que estos nombres españoles vayan "acompañados, ampliamente acompañados, por los de numerosos dramaturgos extranjeros, sean éstos griegos o latinos, medievales o renacentistas, románticos o modernos. Creo que en pocos terrenos artísticos somos tan ignorantes los españoles como en el 
De vanguardias moderadas a heterodoxas: la recepción de la 'patafísica de Alfred Jarry en la prensa literaria española y argentina del siglo xx

teatral" [134]. Y es aquí que, ante la necesidad de llevar a escena obras que el español aún no conoce, Cernuda propone especialmente tres: Lisístrata de Aristófanes, El candelero de Musset y Ubú rey de Jarry. Y concluye con un anhelo: “iquién pudiera asistir, confundido entre el público, al despertar entre nosotros de la escena dramática, cuyo encanto es más poderoso que el de ningún espectáculo!" [136]. Cabe destacar que este artículo publicado en El mono azul estaba acompañado por un aguafuerte de Pablo Picasso de la serie de viñetas "Sueños y mentiras de Franco" (1937), en donde el personaje de Ubú adopta las características del Caudillo español, luciendo peinetas, abanicos, mantillas o emblemas religiosos. Ubú ganará visibilidad en España con Picasso, primero, y con Miró, después, ya que ambos pintores elegirán al personaje de Jarry para aludir a Franco [véanse Calzado 2005; Uberquoi 2006, Klieger Stillman 2009].

\section{Las "segundas vanguardias" argentinas: la recepción heterodoxa de Jarry}

En paralelo al silencio en la prensa española después de la Guerra Civil, ${ }^{8}$ Jarry y la 'Patafísica ingresan en la prensa literaria de las segundas vanguardias argentinas de los años cincuenta y sesenta, en torno a revistas literarias en las que nuestro autor volverá asociado al surrealismo, primero, al invencionismo, después.

Según la periodización de la recepción del surrealismo en Argentina [Poblet Araya 2004:233], tras un primer momento de iniciación y búsqueda vanguardista (1928-1949), le sigue un segundo momento de cristalización y auge (1950-1957), que nos interesa describir especialmente puesto que es el momento en que ocurrirá la importación de Jarry y de la 'Patafísica dentro de las vanguardias, desligada de la impronta simbolista de la primer época. Por último, se da un tercer momento de evolución y transformación (1958-1973), que culmina en el año de muerte del poeta surrealista Aldo Pellegrini. Justamente estos dos últimos momentos relativos al auge y evolución de las segundas vanguardias argentinas coincidirán con el período de consolidación del campo editorial en el país. De ahí que dicha confluencia permita componer un rico panorama de producción libresca y revisteril.

Las vanguardias de la segunda mitad del siglo XX, o "segundas vanguardias", suelen ser caracterizadas como heterodoxas, dado que no estaban alineadas exclusivamente tras un único movimiento: "no fueron muchos los escritores de nuestro país que aceptaron que se los considerara

\footnotetext{
${ }^{8}$ La literatura de Jarry cumple con todos las condiciones para acabar siendo presa de la censura del régimen. A pesar de ello, si bien se trata de una literatura marginal durante la primera etapa franquista (1938-1966), se podría vincular con el humorismo de Miguel Mihura o con el "nuevo teatro" de Fernando Arrabal, Francisco Nieva o Joan Brossa [véase Fólica 2017].
} 
exclusivamente surrealistas. La heterodoxia siempre fue más fuerte que la sujeción a una corriente determinada" [Espejo 2009:29]. Asimismo fueron de baja radicalidad. El poeta Francisco Madariaga describe al surrealismo americano afirmando que "no es protesta sino boda" y no sirve tanto "para rechazar el mundo sino para celebrarlo" [en Prieto 2011:370]. Su innovación se centró, sobre todo, en el plano estético y en el humor, "en especial, en el humor negro y en una capacidad de captar situaciones absurdas" [Pichon Rivière 1973]. En ese sentido, las segundas vanguardias fueron más reformistas o continuadoras que rupturistas, es decir, profundizaron la vía abierta en la década de los años veinte a cargo de las vanguardias "criollas", intensificándola, a su turno, con el humor.

En referencia a los actores y composición de estos movimientos, cabe señalar que el panorama vanguardista en Argentina, durante la segunda mitad del siglo XX, tuvo como figura tutelar al poeta Aldo Pellegrini (1903-1973). Además de fundar el primer grupo surrealista en un idioma distinto al francés en 1926, Pellegrini compuso una obra peculiar que combinó teatro, ensayo y, especialmente, poesía. También ejerció como antólogo y traductor: realizó una Antología de poesía surrealista (Fabril Editora, 1961), que fue alabada y autorizada por el mismo A. Breton. En ella buscó presentar un balance histórico del movimiento desde una posición excéntrica, rescatada en su prólogo como un lugar de libertad:

\footnotetext{
La distancia geográfica, el no haber participado directamente en las actividades del mismo (con toda la carga de conflictos personales que eso significa) puede quizás haber prestado al autor cierta independencia de criterio; y conste que no se hace referencia a una utópica objetividad, cosa que resulta prácticamente imposible, puesto que fatalmente cada uno sigue el camino que le imponen las propias tendencias personales. [Pellegrini 1961:9]
}

Además de organizar la exposición "El Surrealismo en Argentina" en el centro de experimentación artística Instituto Di Tella (1967), la constante actividad de Pellegrini en el campo artístico se vio plasmada en la continua promoción y codirección de revistas literarias y culturales, lugar privilegiado de manifestación de los movimientos vanguardistas. Entre los años cincuenta y sesenta, el surrealismo se hace presente en las revistas A partir de cero (1952-1954), Boa (1958-1960) y Cero (1964-1967). Por otro lado, se desarrollaron publicaciones de vanguardia más inclusivas y heterodoxas opuestas al arte representativo y asociadas al invencionismo, la abstracción geométrica o la neofiguración, como Ciclo (1948-1949), Letra y Línea (1953-1954), Poesía Buenos Aires (19501960) o Madí (1947-1954). 
De vanguardias moderadas a heterodoxas: la recepción de la 'patafísica de Alfred Jarry en la prensa literaria española y argentina del siglo xx

Estos dos grupos de revistas dan cuenta de un rico ambiente de intercambio y debate en la época de las segundas vanguardias en Argentina. Por ejemplo, Poesía Buenos Aires celebra la publicación de revistas surrealistas como A partir de Cero por su "contribución al esclarecimiento de la conciencia poética", pero inmediatamente la acusa de "favorecer, en nombre del automatismo, el absurdo, la vacuidad, la nulidad de la expresión" y, sobre todo, de convertir el método de composición surrealista en una pura "retórica del lenguaje automático", manifiesta en una "fraseología surrealista". A pesar de no coincidir en el método de escritura, consideran que la existencia de un grupo surrealista en Argentina es útil para despertar, en realidad, el interés por nuevos movimientos estéticos.

En general, se establecen fructíferas relaciones entre los escritores y artistas que publicaban en las distintas revistas y, si bien algunas son más fieles a un movimiento, todas ellas apuntan a una caracterización más inclusiva del panorama artístico local en la segunda mitad del siglo XX. Muchos de sus colaboradores escribieron para revistas de los dos grupos, tal y como hizo Juan Esteban Fassio (Buenos Aires 1924- Barcelona 1980), mediador cultural entre Francia y Argentina, ${ }^{9}$ en el que nos detenemos porque fue el traductor e introductor de Jarry y de la 'Patafísica en Argentina. ${ }^{10}$

Como el surrealismo era el movimiento de vanguardia que contaba con más renombre, Fassio se sirvió estratégicamente, primero, de una plataforma surrealista más ortodoxa como A partir de cero, publicando collages y mencionando a Jarry junto a autores como Artaud, Baudelaire, Cendrars, Michaux, Tzara, entre otros [Minguzzi 2013]. Luego, en Letra y Línea, revista más abierta a todo tipo de vanguardia que dedicó un número al dadaísmo (julio de 1954), publicó su ensayo "Alfred Jarry y el Colegio de 'Patafísica", que resultó el primer trabajo local de divulgación del autor, precediendo a la primera traducción castellana de su obra (Ed. Minotauro, 1957). En él, Fassio describe la entonces ignota 'Patafísica como movimiento antecesor del surrealismo. Planteando un linaje inverso, Fassio deja ver entre líneas que la intuición surrealista ya había sido experimentada antes por la 'Patafísica y, en ese sentido, escribe: "en este punto, como en muchos otros, las investigaciones y descubrimientos de Jarry coinciden con las más vitales intenciones del Surrealismo; Breton, Duchamp y Péret no han dejado de declararlo expresamente" [Fassio 1999:56]. Por último, terminó vinculando la 'Patafísica con el invencionismo, cuyas ideas sobre la abstracción resultan más afínes al universo jarryano, ya que si bien el automatismo está presente, no se promueve uno de tipo inconsciente, sino de carácter crítico sin perder por ello sus características lúdicas. Por último, Fassio se relacionó con Madí, revista

\footnotetext{
${ }^{9}$ En la semblanza que hace de él el investigador argentino Jorge Rivera [1997:220], leemos que fue: "[...] un inventor, imaginero, ensayista, dibujante, traductor, compilador, patafísico, bibliófilo y pensador heterodoxo [...]; uno de los mayores y más sutiles conocedores y divulgadores del arte y la literatura de vanguardia, de la que llegó a poseer una de las bibliotecas mejor provistas de la Argentina (junto con las de Elías Piterbarg y Enrique Pichon-Rivière), como piezas auténticamente curiosas y fundamentales".

${ }^{10}$ Para más detalles de su figura, véanse los artículos Fólica [2012:141-149], Fólica [en prensa].
} 
asociada la abstracción rioplatense, participando en la tercera exposición de Madí en noviembre de 1946 [Cadenas Cañón 2012].

Cabe señalar que Fassio era miembro del Collège de 'Pataphysique, de cuya existencia se enteró leyendo un artículo en Les Lettres nouvelles, a principios de los años cincuenta. Ingresó en el Collège el 21 de julio de 1952 (8 del Tantan de 79 Ep., según el calendario patafísico) como un "optimate" (carga que dentro de la jerarquía del Collège engloba a vicecuradores, sátrapas, regentes, proveedores y datarios). ${ }^{11}$ A continuación, fue designado como "proveedor-propagador en Mesembrinesia Americana, Administrador Antártico, Gran Competente de la Orden de la Gran Gidouille" y encargado de la "Regencia y Cátedra de Trabajos Prácticos Rousselianos" (su nombre es mencionado por primera vez en el número 25 de Cahiers du Collège de 'Pataphysique de 1957).

Colaboró con frecuencia en el Collège traduciendo al castellano, por ejemplo, el artículo de Roger Shattuck, "Au seuil de la 'Pataphysique", y publicando artículos bajo seudónimos en los Dossiers (1957-1965), revista signada por la fuerte presencia de B. Vian y E. Ionesco en sus páginas. Allí también aparecen artículos o pastiches sobre J. L. Borges ( $n^{\circ} 4,5$ y 13 ), en los que se celebra el carácter patafísico del autor argentino si bien se condena su postura política-dado que Borges había visto con buenos ojos el golpe militar al entonces presidente Juan Domingo Perón en 1955-, que es juzgada como un "factible error humano" (en Dossiers 4, p. 61- 62):

\footnotetext{
Et l'humain s'excuse par l'humain (c'est si humain d'être humain qu'avec un peu d'humanité on songe que dans les "humanités" ça comptera peut-être peu ou point). Et pour nous pataphysiciens, il reste que Borgès a célébré avec un éclat et une profondeur sans pareilles, une Pataphysique, dont il me semble pas avoir eu la connaissance historique en l'oeuvre de Jarry. Qui d'entre nous n'a pas été forcé de songer que Tlön, c'est le Collège?
}

En el artículo "Borgès et la lettre" (n 26, p. 71-72), se analizan los errores en la traducción al francés de la obra Borges publicada por la Nouvelle Revue Française. El texto está firmado por Jesús Borrego Gil, posible seudónimo de Fassio y anagrama de Jorges Luis Borges. En la publicación Subsidia Pataphysica, dos artículos del mismo Borrego Gil refieren a Bustos Domecq y a Borges (en $\mathrm{n}^{\circ}$ 16-17 y no 24-25). Así pues, Borges, al igual que Macedonio Fernández, Cortázar y el autoproclamado rey de la Patagonia, Orelien Toussan, serán menciones frecuentes del Collège en relación con la producción patafísica argentina, mediadas casi siempre por la figura de Fassio.

\footnotetext{
${ }^{11}$ Para un estudio de la organización jerárquica del Collège así como de su peculiar calendario, véase Hugill [2012:113-136].
} 
De vanguardias moderadas a heterodoxas: la recepción de la 'patafísica de Alfred Jarry en la prensa literaria española y argentina del siglo xx

Motivado por esta relación con el Collège de París, Fassio funda -junto con su amigo Álbano Rodríguez- el primer instituto patafísico extranjero (Instituto de Estudios 'Patafísicos de Buenos Aires, IEPBA) en 1957. En el marco del IEPBA, Fassio elabora un planisferio para la revista estadounidense Evergreen Review (1960) afiliada al moviento beatnik, también boceta un posible monumento en homenaje a Jarry para emplazar en Buenos Aires.

Además se interesa por las "máquinas inútiles" de Marcel Duchamp; de quien recibió de regalo una Boîte-en-valise en agradecimiento por una crítica a la obra "El gran vidrio" publicada en la prensa por el argentino. Fassio también compartía aspiraciones vanguardistas en torno a la estética de la máquina afines con el grupo Madí, buscando cierta poetización de los objetos. Así, en su artículo publicado en Letra y Línea, se interesa por las máquinas ideadas por Jarry y presentes en sus obras: la "máquina de pintar" del doctor Faustroll, la "máquina amatoria" del Supermacho y la "máquina de descerebrar", que usaba Ubú para gobernar extrayendo los sesos.

En esa línea, Fassio crea dos "máquinas de lectura" que promueven un automatismo de carácter reflexivo, combinando el gesto crítico con el lúdico. La máquina de carácter inútil no produce un producto sino mecanismos y, en ese sentido, deja en evidencia sus procedimientos.

El modo de funcionar de estas máquinas resulta afín a una concepción de lengua y de escritura antireferencial, como la compartida por Raymond Roussel y por el propio Jarry, centrada en aspectos formales de la lengua. En Cómo escribî algunos de mis libros, Roussel explicita sus "procedimientos", basados en la creación a partir de la homonimia y la analogía. La primera máquina creada por Fassio es justamente para leer Nuevas Impresiones de África de Roussel. Esta obra, de estructura arborescente, exige al lector volver siempre las páginas hacia adelante y hacia atrás y a casi olvidar el hilo conductor principal. En la descripción de la máquina, Fassio propuso separar la obra en seis series de textos ubicados entre diferentes paréntesis, ordenados en tarjetas identificadas con los colores rojo, azul, amarillo, verde, violeta y naranja (idea de Roussel para separar las distintas partes del libro) [Rivera 1997:223-224].

Más adelante, Fassio realizó una máquina para la lectura de Rayuela (1963) o Rayuela o-matic. Allí planteó una lectura a partir de combinaciones que espacializaban el texto y que retomaban la propuesta hecha por el propio Cortázar, quien había elaborado un posible orden de seguimiento de los capítulos al comienzo del libro en la "guía de lectura". Fassio envió el proyecto, una suerte de "antimanual", a Julio Cortázar, con quien tuvo un intercambio de afectuosas cartas por intermediación 
de su editor, Francisco Porrúa, en la que se trataban de "cronopios" e ideaban juntos una "antología de literatura insólita" o de "humor fantástico". En una carta dirigida a Fassio y Porrúa (18 de agosto de 1964), Córtazar relata la "conquista de París por Fassio":

\footnotetext{
La conquista de París por Fassio se está cumpliendo de una manera tan ominosa como sistemática.

[...] Mi plan está trazado y es secamante genial: tan pronto aparezca en París la versión francesa de Rayuela, produzco y hago publicar un artículo considerable sobre los DOCUMENTOS, con fotos, planos, recuerdos de infancia, retratos de Sara a los 3 años (ya lo podés ir imaginando, che, o pongo uno falso de una bebita espantosa con todos los pelos parados) y otros aportes iconográficos adok. Personalmente, después de haber desplegado la totalidad de los DOCUMENTOS a mi cuarto de trabajo (más conocido en casa por el quilombito), he pasado largas horas soplando en mi trompeta para el horror de los vecinos, pues eso constituye mi más segura manera de entrar a fondo en cualquier cosa que me interesa de verdad y que quiero conocer por dentro. [Cortázar 2012:457]
}

Y así lo hace, ya que Cortázar escribe el artículo "De máquinas célibes" que publica en La vuelta al día en 80 mundos, en el que explica el invento del Rayuela-o-matic y celebra la importancia de la máquina dentro del lenguaje como un modo de pensar la lengua alejada de la referencialidad al privilegiar el mecanismo por sobre el referente [Cortázar 1967:123-135].

La relación literaria de Fassio con el escritor Julio Cortázar y con el editor de Minotauro, Francisco Porrúa, queda significativamente sellada con la edición de Historia de cronopios y famas, ya que fue editado por Porrúa en 1962 con con una cubierta compuesta por Fassio. Este libro consagra la entrada del humor de forma autónoma a las letras argentinas, alejado ya de las páginas costumbristas de revistas, y más próximo a la tradición de la literatura fantástica [Rivera en Gasalla 2003:115]. Cortázar será, además, un importante introductor de Jarry y de la 'Patafísica en Argentina, a través de su mención en la obra crítica y en su novela Rayuela, en la que defiende la creación a partir de la "ley de la excepción" [Fólica 2012:141-149].

En cuanto la traducción de Ubú rey, hemos dicho que 1957, además de ser el año de creación del IEPBA, es el del lanzamiento de la primera traducción al castellano, a cargo de Fassio y en colaboración con Enrique Alonso. Esta es editada por Minotauro, responsable de introducir la ciencia ficción, género no solo inexistente en momentos de su producción francesa, sino también de flamante desambarco en Sudamérica. El editor Porrúa quiso importar este género de una forma singular, vinculándolo con la tradición latinoamericana de lo fantástico y alejándolo del "hard 
De vanguardias moderadas a heterodoxas: la recepción de la 'patafísica de Alfred Jarry en la prensa literaria española y argentina del siglo xx

science-fiction" y de su estética pulp [Fólica 2017: 119-128]. En ese sentido y en lo que respecta a las cubiertas de sus libros, optó por una pintura abstracta de artistas argentinos como los del movimiento "Otra figuración" en consonancia con las "segundas vanguardias" [Castagnet 2015].

\section{Conclusión}

Hasta aquí hemos trazado la tímida pero persistente circulación de Alfred Jarry y su Ubú, así como las ideas de la 'Patafísica a él asociadas, en la prensa literaria de España y Argentina, atravesada por los movimientos de vanguardias.

En un primer momento, hemos dado cuenta del gesto inicial de la prensa literaria de las tres primeras décadas del siglo XX de recibir las vanguardias europeas desde un marco simbolista anterior. En ellas Jarry es recuperado como poeta del simbolismo, si bien él mismo se había preocupado por dinamitar sus preceptos desde la escena del Théâtre de l'CEuvre. En clave local se lo asocia con géneros nuevos como el esperpento español o con el criollismo vanguardista y políglota argentino. Más allá de las diferencias entre las vanguardias de España y Argentina, cristalizada en la polémica en torno al "meridiano intelectual" y la defensa ora de la unidad lingüística del español ora de la diversidad fonética criolla, hemos advertido que en ambos casos, los escritores practicaban un vanguardismo moderado y conservador, tal y como pudo ilustrar la traducción decorosa del poema "Le bain du roi" en Martín Fierro. En esta última revista, la recuperación de la literatura francesa, de la que Jarry es un ejemplo, colabora con el planteamiento de la emancipación intelectual de España y de sus pretensiones de injerencia artística -y editorial- en América Latina.

En un segundo momento, durante la Guerra Civil española, hemos dado cuenta de un intento de politización de la obra de Jarry en la prensa cultural republicana. Así pues, El mono azul, bajo la pluma de Cernuda, recuperó el personaje de Ubú con miras a la sátira y a la crítica social y política, más que a la innovación formalista de un lenguaje antimimético, como sugería el propio Jarry en su contexto francés. Creemos que esta primera referencia de Cernuda es clave ya que marcó el tono de la recepción posterior que tendría Ubu en España, asociada a la sátira política y con Franco como blanco dilecto.

Por último, opuesto al silencio de posguerra de esos años españoles en las publicaciones culturales, hemos estudiado cómo las vanguardias heterodoxas argentinas de los años cincuenta y 
sesenta recuperaron la obra de Jarry y sus ideas sobre la 'Patafísica en las revistas culturales de la época asociándolas, primero, al surrealismo y, luego, al invencionismo y la abstracción, más afines con el mundo estético del autor francés. En ese sentido, rescatamos la figura de su introductor Juan Esteban Fassio, por ser no solo ensayista, antólogo, ilustrador o inventor sino también el primer traductor en castellano de la pieza Ubu roi.

Así pues, por las páginas de las revistas de las vanguardias argentinas y españolas del siglo XX, Jarry y su personaje Ubú, doctor en 'Patafísica, circularon, a veces con un paso tímido y otras con mayor firmeza y desparpajo. Transportando ideas propias, como las relativas a la literatura antimimética celebrada por las vanguardias, o ayudando a activar las ajenas, como las referenciales propias de la sátira política española, Ubú acabó reuniendo "los dos hemisferios" a fuerza de pisar con la huella "de su pie patagón".

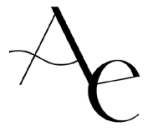


De vanguardias moderadas a heterodoxas: la recepción de la 'patafísica de Alfred Jarry en la prensa literaria española y argentina del siglo xx

\section{BIBLIOGRAFÍA}

AA. VV.: Martín Fierro 1924-1927. Edición facsimilar, ed. de Horacio Salas. Buenos Aires: Fondo Nacional de las Artes, 1995.

ALONSO, Rodolfo (dir.): Poesía Buenos Aires. 1950-1960. Antología íntima. Buenos Aires: Ediciones del Dock, 2009.

ANOLL VENDRELL, Lídia: "Sobre las traducciones españolas del teatro simbolista en lengua francesa», en Francisco Lafarga \& Roberto Dengler (eds.), Teatro y traducción. Barcelona: UPF, 1995, pp. 177-184.

BARÓN, Emilio: «Luis Cernuda, traductor (sus versiones de poemas franceses, alemanes e ingleses)», Traducir poesía. Luis Cernuda, traductor. Almería: Universidad de Almería, 1998, pp. 103-105.

BAYLEY, Edgar: «Invencionismo», en Raúl Gustavo Aguirre \& Nicolás Espiro, El Movimiento Poesía Buenos Aires. Literatura argentina de Vanguardia. Buenos Aires: Fraterna, 1979, pp. 75-76.

BÉHAR, Henri: «Jocrisse ou gendelettre? Jarry tel qu'en lui-même», Les Nouveaux Cahiers de la Comédie Française 5 (Alfred Jarry). París: mayo de 2009, pp. 7-14.

BOURDIEU, Pierre: «Las condiciones sociales de la circulación de las ideas», Intelectuales, política y poder, trad. de A. Gutiérrez. Buenos Aires: Eudeba, 1999, pp. 159-171 (ed. orig. 1989; reed. 2002).

CADENAS CAÑÓN, Isabel: «Juan Esteban Fassio, orígenes de la 'Patafísica porteña», 2012. http:// clacsnyublog.com/2012/06/19/juan-esteban-fassio-origenes-de-la-patafisica-portena-ppparte-primera-pp/.

CASTAGNET, Martín Felipe: "Las portadas de Ediciones Minotauro y la renovación de la ciencia ficción », IX Congreso Internacional Orbis Tertius de Teoría y Crítica Literaria. Ensenada: 3-5/06/2015. http://www.memoria.fahce.unlp.edu.ar/trab_eventos/ev.8627/ev.8627.pdf.

CERNUDA, Luis: «Sobre la situación de nuestro teatro» [1937], Obras completas III. Barcelona: RBA / Instituto Cervantes. Barcelona: 2007a, pp. 131-133.

: «Un posible repertorio teatral»[1937], Obras completas III. Barcelona: RBA / Instituto Cervantes, Barcelona: 2007b, pp. 134-136.

COLLÈGE DE 'PATAPHYSIQUE: Dossiers du Collège de 'Pataphysiques, 1957-1965.

CORTÁZAR, Julio: Historia de cronopios y de famas. Buenos Aires: Sudamericana, 1962. - La vuelta al día en ochenta mundos I. Buenos Aires: Siglo XXI. 2009 (ed. orig. 1967). : Cartas (1955-1964) II. Buenos Aires: Alfaguara, 2012. 
EL MONO AZUL: http://periodicosregalo.blogspot.com.es/2013/08/revista-el-monoazul-1936-1939.html.

ESPEJO, Miguel: «Los meandros surrealistas», en Noé Jitrik (dir.), Historia crítica de la literatura argentina (Rupturas) 7. Buenos Aires: Emecé, 2009, pp.13-47.

EVEN-ZOHAR, Itamar: «The Position of Translated Literature within the Literary Polysystem» [1978], Poetics Today 11: 1, 1990, pp. 45-51.

ESPÓSITO, Fabio: «Los editores españoles en la Argentina: redes comerciales, políticas y culturales entre España y la Argentina (1892-1938)», en Carlos Altamirano (dir.), Historia de los intelectuales en América Latina II. Los avatares de la "ciudad letrada" en el siglo XX. Buenos Aires / Madrid: Katz Editores, 2010, pp. 515-536.

FÓLICA, Laura: «Relaciones patafísicas: J. E. Fassio, traductor de Jarry y personaje de Cortázar», en Francisco Lafarga \& Luis Pegenaute (eds.), Aspectos de la historia de la traducción en Hispanoamérica: autores, traducciones y traductores. Vigo: Academia del Hispanismo, 2012, pp. 141-149.

_ : «De ninguna parte a Ubuenos Aires. La introducción de 'Patafísica en Argentina», en AA.VV, Transbordos literarios. Correspondencias y confines en la literatura hispánica (ALEPH). Sevilla: Renacimiento (En prensa).

— : «Francisco Porrúa, un traductor romántico para la ciencia ficción», Lenguas Vivas 13, noviembre de 2017, pp. 119-128.

: «Reescrituras de la espiral: producción y recepción de Ubu roi de Alfred Jarry en Francia y su traducción y recepción en Argentina y España (1896-2016)», tesis doctoral, enero de 2017, http://hdl.handle.net/10803/401859.

GALLEGO ROCA, Miguel: «De cómo no fueron posibles en español las traducciones vanguardistas», en Luis Pegenaute (ed.). La traducción en la Edad de Plata. Barcelona: PPU, 2001, pp. 41-48. : «De las Vanguardias a la Guerra civil», en Francisco Lafarga \& Luis Pegenaute (eds.), Historia de la traducción en España. Salamanca: Editorial Ambos Mundos, 2004.

GARCÍA HAYMES, Mateo: «Una vanguardia conservadora. La revista Martín Fierro ante la emergecia de las industrias culturales (1924-1927)», Letras históricas 4, 2011, pp. 75-92.

GASALLA, Barbara: «Literatura argentina y humor. Warnes y la institución literaria», en Mónica Bueno \& Miguel Ángel Taroncher (coords.), Centro Editor de América Latina. Capítulos para una historia. Buenos Aires: Siglo XXI, 2003, pp. 107-117. 
De vanguardias moderadas a heterodoxas: la recepción de la 'patafísica de Alfred Jarry en la prensa literaria española y argentina del siglo xx

HUGILL, Andrew: 'Pataphysis. A Useless Guide. Massachusetts: The MIT Press, 2012.

JARRY, Alfred: CEuvres Complètes I. París: Gallimard, 1972.

: Ubú rey, ed. de J. E. Fassio, trad. de J. E. Fassio \& E. Alonso. Buenos Aires: Minotauro, 1957 (reed.: Buenos Aires, CEAL, 1971, 1976, 1980).

KLIEGER STILLMAN, Linda: «Alfred Jarry et Joan Miro», L'Étoile-Absinthe 123-124, 2009, pp. 59-74. Les archives du spectacle: https://www.lesarchivesduspectacle.net.

MIHURA, Miguel: Tres sombreros de copa [1932], ed. de J. Rodríguez Padrón. Madrid: Cátedra, 1992. MINGUZZI, Armando: El Surrealismo y sus derivas. Madrid: Universidad Autónoma de Madrid, 2013. http://www.uam.es/proyectosinv/surreal/que.html.

PELLEGRINI, Aldo: Antología de la poesía surrealista, Buenos Aires, Fabril, 1961.

PICHON RIVIÈRE, Marcelo: «El Surrealismo argentino de París a Buenos Aires», Revista Crisis, 1974. http://www.magicasruinas.com.ar/revistero/esto/revdesto230.htm.

POBLET ANAYA, Kira: «El Surrealismo argentino y su praxis», en Carlos García \& Dieter Reichardt (eds.). Vanguardias Literarias. Argentina. Ururguay. Paraguay. Fráncfort / Madrid: Vervuert / Iberoamericana, 2004, pp. 233-243.

PRIETO, Martín: Breve historia de la literatura argentina, Buenos Aires, Taurus, 2011.

REVISTAS DE LA EDAD DE PLATA: http://www.edaddeplata.org/revistas_edaddeplata/.

RIVERA, Jorge: «Fassio: las máquinas de leer laberintos», Postales electrónicas. Buenos Aires: Atuel, 1997, pp. 219-226.

SARLO, Beatriz: "Vanguardia y criollismo: La aventura de Martín Fierro», en Beatriz Sarlo \& Carlos Altamirano. Ensayos argentinos. De Sarmiento a la vanguardia. Buenos Aires: Ariel, 1997a, pp. 211-268.

: Oralidad y lenguas extranjeras», en Beatriz Sarlo \& Carlos Altamirano. Ensayos argentinos. De Sarmiento a la vanguardia. Buenos Aires: Ariel, 1997b, 269-288.

SCHUH, Julien: Alfred Jarry. Le Colin-maillard cérébral. París: Honoré Champion. 2014.

SORIA OLMEDO, Andrés: Vanguardismo y crítica literaria en España. Madrid: Istmo, 1988.

SOTO CALZADO, Inocente: «Ubú Picasso», Archivo Español de Arte, LXXVIII, 2005, pp. 353-368. $<$ http://archivoespañoldearte.revistas.csic.es>.

UBERQUOI, Marie-Claire, Rosa María Malet et al. Joan Miró i el món d’Ubú. Ubu aux Baléares. Palma de Mallorca: Fundació Es Baluard / Museu D’Art Modern i Contemporani de Palma, 2006. 